\title{
LAS VÍCTIMAS ANTE EL PRECIPICIO DE LA VERDAD: UNA CUESTIÓN DE JUSTICIA TRAS EL DEBILITAMIENTO DE GIANNI VATTIMO
}

\author{
Jairo Marcos ${ }^{1}$ \\ Universidad Nacional de Educación a Distancia (UNED) \\ Universidad Nacional Autónoma de México (UNAM) \\ (D) https://orcid.org/0000-0002-3738-1199 \\ E-mail: jmarcos@desplazados.org
}

\section{RESUMEN:}

El siglo XXI inaugura la era de la post-Verdad como espectáculo visual que favorece las apariencias por encima de todo lo demás. Pero de forma esquizofrénica, la aceptación social de la mentira choca frontalmente con la mantenida idealización de la Verdad como espejo objetivo de los hechos, que continúa siendo la hoja de ruta regulatoria de Occidente y su eurocentrismo. Las víctimas parecen quedar así atrapadas así entre el precipicio del espejo objetivante y el abismo de la post-Verdad espectacularizada, dos formas de absolutización de la Verdad al vaivén de las voluntades e intereses de poder. Este artículo parte de esta bipolaridad paradójica contemporánea, para, a través del debilitamiento epistémico de la Verdad propuesto por el filósofo Gianni Vattimo, atajar la cuestión de dignidad y la justicia de las víctimas. La debilitación epistémica de la Verdad que plantea Vattimo abre efectivamente las posibilidades para una transformación democrática, pero nada garantiza qué ni quiénes vayan a sacar partido de esa apertura debolista. Para ser transformadora, la Verdad deja de ser absoluta, incluso de pretenderlo, pero sin perder por ello la referencia de criterios que habitan las vidas humanas dignas como fuente corporal.

PALABRAS CLAVE: Post-Verdad; Verdad; Vattimo; Víctimas.

\section{THE VICTIMS IN FRONT OF THE ABYSS OF TRUTH: A QUESTION OF JUSTICE AFTER THE WEAKENING OF GIANNI VATTIMO}

\begin{abstract}
:
The $21^{\text {st }}$ century opens the post-Truth era as a visual spectacle that favors appearances above everything else. But in a schizophrenic way, the social acceptance of the lie directly clashes with the continued idealization of the Truth as an objective mirror of the facts, which continues to be the regulatory road map of the West and its Eurocentrism. The victims seem thus to be trapped in between the precipice of the objectifying mirror and the abyss of the spectacularized post-Truth, two forms of absolutization of the Truth swinging from one the wills to powers of interest. This article starts from this contemporary paradoxical bipolarity, in order to, through the epistemic weakening of the Truth proposed by the philosopher Gianni Vattimo, address the question of dignity and justice of the victims. The epistemic weakening of the Truth that Vattimo raises effectively opens the possibilities for a democratic transformation, but nothing guarantees what or who will take advantage of that debolist opening. In order to be transformative, Truth ceases to be absolute, even to claim it, but it cannot lose the reference of criteria that inhabit worthy human lives as a corporal source.
\end{abstract}

KEYWORDS: Post-Truth; Truth; Vattimo; Victims.

\footnotetext{
${ }^{1}$ Doctorando Internacional en Filosofía - Universidad Nacional de Educación a Distancia (UNED), Madrid Espanha y Universidad Nacional Autónoma de México (UNAM), Ciudad de México - México
}

MARCOS, Jairo. Las víctimas ante el precipicio de la verdad: una cuestión de justicia tras el debilitamiento de Gianni Vattimo. Griot : Revista de Filosofia, Amargosa - BA, v.19, n.1, p.159-173, fevereiro, 2019. 
En medio de un irónico juego de interpretaciones, el debilitamiento de los fundamentos últimos arrastra consigo la Verdad. La ontología hermenéutica radical y nihilista de Vattimo la convierte en algo innecesario, puede que incluso inconveniente para el ser humano: "La verdad como absoluta correspondencia objetiva, entendida como última instancia y valor de base, es un peligro más que un valor" (VATTIMO, 2010/2009, p. 29)2. La amenaza se corresponde con la imposición de lo Mismo (o los mismos), que fabrica 'lo real' desde su privilegiada posición ${ }^{3}$, sobre lo Otro (o nos-Otras, las víctimas). Precisamente esta violencia de la Verdad, "que puede tornarse fácilmente una imposición sobre nuestra propia existencia" (VATTIMO \& ZABALA, 2012/2011, p. 32), es lo que el filósofo turinés pretende evitar con el ocaso de las estructuras fuertes. Y sin embargo.

Y sin embargo las víctimas siguen ahí, por mucho que Vattimo debilite la Verdad mediante una cuidadosa escucha del silencio del no-Ser, dibujando esa parábola hermenéutica que no destruye (Überwindung) la Verdad, sino que la distorsiona rememorativamente (Verwindung). ¿Adiós a la Verdad, hacia una transformación de la Filosofía? Puede, tal vez, quizá. Pero ¿acaso el debilitamiento de la Verdad, hacia las verdades debolistas, no invalida cualquier crítica, sugiriendo la aceptación de lo Mismo ya dado, la Totalidad y su Razón excluyente? ¿Hacia qué dirección puede si quiera defenderse una transformación teniendo en cuenta la pertenencia a una época caracterizada por la disolución de los principios? "No vivimos tiempos fáciles para la verdad - ¿alguna vez lo fueron?- [...], con la discriminación hiriente de que lo que para unos es dificultad que abordamos en la reflexión teórica, para otros es tragedia cotidiana" (PÉREZ-TAPIAS, 2007, p. 45).

\section{La post-Verdad de la sociedad massmediática virtualizada}

La tecnocomunicación globalizada, ese intercambio frenético de mensajes, ese ir-y-venir de imágenes y sonidos provenientes del UNIverso comunicativo, debilita socialmente la Verdad hasta levantar sospechas acerca de su existencia misma. El siglo XXI inaugura la era de la post-Verdad, un fangoso terreno en el que lo verdadero y lo falso pasan a un segundo plano. "La esfera pública se ha desordenado y sentimentalizado por efecto de la tecnología" (ARIAS, 2017, p. 70). Esta desorientación hacia lo emocional responde a una época de velocidad acelerada, de tiempos y espacios contraídos, en la que las esperas temporales y las fronteras físicas son apenas un mal trago.

La post-Verdad se construye con el vertiginoso intercambio de inputs que revolotean en el ambiente aireados por los medios de comunicación y por las redes sociales, en un bombardeo privilegiadamente visual que favorece las apariencias por

\footnotetext{
2 Esta irónica (in)humanidad de la Verdad la condensa literariamente Unamuno en un diálogo entre dos de sus personajes: "¿¿La verdad? La verdad, Lázaro, es acaso algo terrible, algo intolerable, algo mortal; la gente sencilla no podría vivir con ella" (UNAMUNO, 2017/1931, p. 29).

3 "Únicamente los fuertes determinan la verdad, porque solo ellos cuentan con las herramientas para conocerla, practicarla e imponerla" (VATTIMO \& ZABALA, 2012/2011, p. 26).

4 'Postverdad' fue elegida la palabra del año en 2016 por Oxford Dictionaries, la sociedad que edita el Diccionario de Oxford, aduciendo la pérdida de influencia de los hechos en favor de las emociones o las creencias personales a la hora de configurar la opinión pública. Ese mismo ejercicio coincidió, entre otros, con acontecimientos como la victoria de Donald Trump en Estados Unidos, el rechazo colombiano al acuerdo de paz entre las FARC y el Gobierno de Juan Manuel Santos, además de la irrupción del Brexit en el interior de la Unión Europea.
}

MARCOS, Jairo. Las víctimas ante el precipicio de la verdad: una cuestión de justicia tras el debilitamiento de Gianni Vattimo. Griot : Revista de Filosofia, Amargosa - BA, v.19, n.1, p.159-173, fevereiro, 2019. 
encima de todo lo demás ${ }^{5}$. Mediatizada y viralizada, la Verdad se hace pasar por la post-Verdad convertida en un espectáculo que "no quiere llegar a ninguna otra cosa que a sí mismo" (DEBORD, 1995/1967, p. 12). Y es así, entre las apariencias de verdad mediatizadas por la imagen repetida reiterativamente, como el propio espectáculo se convierte en lo real ${ }^{6}$ : la Verdad es lo que aparece, la Verdad es lo que aparece, la Verdad es lo que aparece.

La debilitación epistémica de la Verdad que plantea Vattimo abre efectivamente las posibilidades para una transformación democrática ${ }^{7}$, al prevenir frente a cualquier receta ya cerrada de lo que debe ser o hacerse, de lo que ha de imponerse en función de la Verdad más verdadera. Verdad absoluta alienante ${ }^{8}$. Pero nada garantiza qué ni quiénes vayan a sacar partido de esa apertura debolista. Y sucede que la mentira aprovecha las grietas para despojarse de sus vergüenzas y por vez primera deja de ser percibida como un reprobable suicidio colectivo9: "Aceptar que estamos en la era de la posverdad implica introducir la arbitrariedad en [...] el lenguaje, utilizarlo en beneficio de los intereses de quien habla, desconsiderar las reglas gracias a las cuales [...] es un instrumento eficaz de comunicación" (CAMPS, 2017, p. 93).

Bienvenidos a la post-Verdad, la resignación sumisa a las meras apariencias de Verdad. Y es que, la clave no está tanto en que la Verdad se haya diluido entre el bombardeo massmediático y viralizado de pseudo-noticias (fake news), sino la constatación de que ya no importa que sean falsas mientras reconforten las preconcepciones adquiridas y refuercen los vínculos que identifican al Nosotros cerrado, mientras lo distancian del ellos proyectado como enemigo. La aceptación de la mentira universaliza así la sofística más perversa, potenciando únicamente la función simbólica de la comunicación, la que emocionalmente crea identidad colectiva y, a la postre, diferencia entre las vidas que merecen ser vividas y las que no: "La pertenencia a un grupo es una necesidad cada vez más imperiosa. [...] No importa ya que las noticias sean verdad o mentira, lo que importa es que su uso sirva para reforzar al grupo interno y atacar al externo" (CERVERA, 2017, p. 13).

\footnotetext{
5 "Conectados, pesa más la imagen y el vistazo frente a la lectura y la reflexión pausada" (ZAFRA, 2017, p. 184).

6 "Al mismo tiempo, la realidad vivida se encuentra materialmente invadida por la contemplación del espectáculo, y retoma en sí misma el orden espectacular dándole una adhesión positiva. De los dos lados la realidad objetiva está presente [...]: la realidad surge en el espectáculo, y el espectáculo es real. Esta alienación es recíproca y es el sostén de la sociedad existente" (DEBORD, 1995, 1967, p. 10).

7 "El adiós a la verdad es el inicio, y la base misma, de la democracia. Si existiera una verdad 'objetiva' de las leyes sociales y económicas, [...] la democracia sería una opción por completo irracional: sería mejor confiar el Estado a los expertos" (VATTIMO, 2010/2009, p. 18).

8 "Que haya respuestas objetivamente verdaderas o falsas a todas las preguntas que podamos formular, de manera que la valía del hombre consistiera en conocer verdades, y la virtud humana fuera meramente la creencia verdadera justificada [...] resulta aterrador, pues excluye la posibilidad de que haya algo nuevo bajo el sol, de que la vida humana sea poética y no meramente contemplativa" (RORTY, 1989/1979, p. 350).

${ }^{9}$ La aceptación universal de la mentira conduciría a la muerte social, ya desde el punto de argumentativo de la lógica comunicativa, pues todo colectivo humano está basado en las relaciones (lingüísticas y de otra índole) de confianza entre sus miembros; introducir la mentira como comportamiento aceptado imposibilitaría la comunicación y, sobre todo, minaría las relaciones intersubjetivas (incluso las de un Nosotros cerrado), conduciendo finalmente a la inhumanidad o al suicidio colectivo del ser humano. "Sobre ella [la mentira] no se puede sostener la vida porque, si se generaliza, hace inviable la imprescindible 'con-vivencia'. [...] Por eso, la oposición a ella debe ser frontal. [...] Ello se puede constatar históricamente, pues en todas las culturas hemos convivido con nuestros errores, pero ninguna ha justificado la mentira, por más que en todas se haya padecido y se padezca" (PÉREZ-TAPIAS, 2007, pp. 60-61).
} 


\section{La vigencia del mito de la Verdad como adaequatio}

De forma esquizofrénica, como si la sociedad contemporánea sufriera una bipolaridad paradójica de efectos inusitados, esta aceptación social de la mentira choca frontalmente con la mantenida idealización de la Verdad como espejo objetivo de los hechos, que continúa siendo la hoja de ruta regulatoria más habitual de la Epistemología, de la Política, de las Ciencias, también de la Filosofía, de Occidente y su eurocentrismo; en definitiva, de ese Hombre mayúsculo que sigue empeñado en desembarazarse de su finitud y convertirse bien en Dios o bien en máquina ${ }^{10}$. El vértigo es por tanto mayúsculo, pues ya no solo se trata de evitar que la sociedad abierta quede encerrada bajo los grilletes y el candado de esa Verdad mayúscula temidos por Popper ${ }^{11}$, sino que la apertura vattimiana, aun sin pretenderlo, permite también asomarse a la monstruosidad inhumana de la mentira universal. Las víctimas parecen quedar así atrapadas así entre la espada y la pared, entre el precipicio del espejo objetivante y el abismo de la post-Verdad espectacularizada, dos formas de absolutización de la Verdad al vaivén de las voluntades e intereses de poder.

La Verdad como adaequatio, fiel reflejo de un hecho dado como dato objetivo es la heredera de las Ideas platónicas y sus esencias, inmutables y a la par accesibles ${ }^{12}$; heredera también del Más Allá teológico y su fe en la salvación eterna ${ }^{13}$; heredera de las estructuras mentales kantianas que organizan el mundo fenoménico $^{14}$; heredera del hecho experimentado y verificado del positivismo ${ }^{15}$; herencia igualmente presente en el curso de la historia hegeliana, con presente, pasado y futuro prefijados ${ }^{16}$; y en la revolución marxiana, desde la esencia de la clase obrera $^{17}$. En suma, es la Verdad como correspondencia: $p$ es verdadera si y solo si $p^{18}$.

\footnotetext{
10 "La idea de un Espejo de la Naturaleza totalmente limpio es la idea de un espejo que no podría distinguirse de lo que se ha reflejado y, por tanto, no sería un espejo en absoluto. La idea de un ser humano cuya mente es ese espejo limpio, y que sabe esto, es la imagen [...] de Dios. Puede ser llamado 'Dios' si pensamos en las ventajas de esta situación, o una 'simple máquina' si pensamos en sus desventajas. Desde este punto de vista, [...] es intentar escapar de la condición de hombre" (RORTY, 1989/1979, p. 340).

${ }^{11}$ Los enemigos de la sociedad abierta que identifica Popper son aquellas personas que, creyendo haber alcanzado la Verdad mayúscula, retornan al mundo con la tarea final de conducir a la sociedad para guiarla por la senda de dicha Verdad, con independencia de los medios para conseguirlo. (POPPER, 2006/1945).

12 En la alegoría de la caverna, el conocimiento situado en el mundo inteligible es alcanzable mediante el uso exclusivo de la razón. (Platón, 2000/380 a.e.c.).

13 Por ejemplo, el Dios cristiano de San Agustín es accesible a través de la 'mirada interior' del creyente. (Agustín, 2007/397-398 d.e.c.).

14 También al alcance del hombre, Kant traslada el problema de la Verdad a la mente. Ver KANT, Immanuel: Crítica de la razón pura. Trad. Mario Caimi. Buenos Aires: Colihue, 2007 [Edición original: 1781].

${ }^{15}$ Comte, por ejemplo, propone conocer lo real de las cosas a través de las leyes de la naturaleza, a las que accede a través de la observación, la experimentación y la comparación. (Comte, 1985/1844).

${ }^{16}$ La Historia, y con ella la Verdad hegeliana, sigue un sentido único de Este a Oeste. (Hegel, 1986/1837).

${ }^{17}$ El proletariado marxiano lleva en sí la verdadera revolución. (Marx, 2000/1867).

${ }^{18}$ A principios del siglo XX, el filósofo matemático Tarski precisó semánticamente el alcance de la Verdad como correspondencia: $p$ es verdadera si y solo si $p$, planteamiento en el que $p$ es una entidad lingüística (concretamente, una oración declarativa perteneciente a un lenguaje específico) independiente de la existencia de sujetos cognoscentes. (Tarski, 1999/1944). En una línea similar se expresa el primer Wittgenstein (2010/1921), el del lenguaje como esencia, autoenmendado posteriormente por el segundo Wittgenstein (1999/1953), el del lenguaje como parte de juegos de vida contextuales.
}

MARCOS, Jairo. Las víctimas ante el precipicio de la verdad: una cuestión de justicia tras el debilitamiento de Gianni Vattimo. Griot : Revista de Filosofia, Amargosa - BA, v.19, n.1, p.159-173, fevereiro, 2019. 
El diálogo es apenas otro maquillaje de esta Verdad auténtica previamente dada. Lo ejemplifican los escritos platónicos, en los que quien debe aprender siempre es el no-Ser, aquellos esclavos que, si querían alcanzar el Bien supremo, la luz fuera de la caverna, debían someterse primero a los rigores del método por el que les conducían los privilegiados que habían visto ya la Luz del exterior, personificados en el filósofo-rey ${ }^{19}$. Un consenso que se prolonga en la actualidad, ahora sustituidos los esclavos y los filósofos-reyes, respectivamente, por las periferias y Occidente ${ }^{20}$. Para ambos grupos de antagonistas, los esclavos que refleja Platón y los débiles contemporáneos en quienes piensa Vattimo, la Verdad es algo que ya está ahí como algo dado que pertenece a unos pocos mientras a los muchos se les otorga la capacidad de alcanzarla. No es por tanto el resultado de un acuerdo colectivo, sino el final de un camino prefijado que se impone violentamente, por mucho que llegue revestido de diálogo, como en la actualidad sucede con la teoría de la acción comunicativa de Apel y Habermas ${ }^{21}$.

Violencia porque, dado el fundamento último que la Verdad refleja como adaequatio, el diálogo no puede ser otra cosa que el silenciamiento más o menos temprano del Otro, de quien todavía no conoce esa Verdad dada, pero se supone debe hacerlo" ${ }^{22}$ "Los diálogos excluyen la posibilidad misma de transformación, ya que imponen la verdad a cualquier forma de discrepancia frente al orden [...] predominante" (VATTIMO \& ZABALA, 2012/2011, p. 43).

\section{Las sospechas de Nietzsche y de Heidegger}

Son Nietzsche y Heidegger en quienes Vattimo sustenta sus críticas a esta Verdad como adaequatio. El primero apunta que la Verdad es en realidad aquello que el hombre hace del mundo a través de la técnica, hasta que el 'mundo verdadero' termina convertido en una fábula y el valor de la verdad desemboca en el engaño, fruto de los juegos de fuerzas interesadas, de una voluntad de verdad tras la que se esconde la voluntad de poder (NIETZSCHE, 2001/1889, pp. 57-58). Y así, la verdad y la mentira no responden sino al interesado juego de las apariencias de lo Mismo. La interpretación nihilista nietzscheana trata de abrirse paso frente a tal engaño, hasta llegar a esa calle en la que convergen el conocimiento y la verdad, cruce en el que el filósofo enarbola su verdad alternativa desde los artistas y los escritores como

\footnotetext{
19 Así sucede en el diálogo del Menón, en el cual el esclavo solo comprende la verdad tras someterse a la violencia del diálogo platónico. (Platón, 1987/385 a.e.c., pp. 273-337).

20 "Al igual que Platón, Occidente cree que posee la verdad, es decir, el conocimiento apropiado capaz de guiar el interés de todos los demás" (Vattimo \& Zabala, 2012/2011, pp. 38-39).

21 Vattimo acusa a Apel (1991/1987) y a Habermas (2002/1999) de incurrir en un formalismo trascendental que ignora la finitud humana e identifica nuevamente, bajo el subterfugio del consenso, la Verdad con la pertenencia real de la cosa. "El ideal de transparencia [...] parece peligrosamente [...] próximo a la concepción de la verdad como objetividad certificada por un sujeto 'neutral', que tiene su modelo en el sujeto 'metafísico'. [...] Planteada en estos términos, la teoría de la acción comunicativa podría representar un clamoroso ejemplo de colonización del mundo de vida por parte de una forma de acción específica, la científico-descriptiva" (VATTIMO, 1995/1994, p. 75).

${ }^{22}$ Vattimo analiza una segunda forma de violencia en la Verdad como adaequatio: "Al regresar el esclavo del viaje los otros no solo se burlan de él porque ya no puede ver en la oscuridad, sino que, además, quieren matarlo al pedirles que le sigan. Temen el viaje, es decir, la verdad, porque implica cierta violencia que podría no merecer la pena. [...] La verdad se convierte en violencia no solo para aquéllos que no aceptan dejar la caverna, sino también para quienes regresan a ella" (VATTIMO \& ZABALA, 2012/2011, pp. 39-40).
} 
culmen de lo humano, verdaderamente humano (NIETZSCHE, 2001/1878, pp. 119$150)^{23}$.

Criticando precisamente a Nietzsche por no haber superado la idea de Verdad objetiva y haberse conformado con el choque de voluntades, Heidegger recorre una senda similar a través del círculo no-vicioso de comprensión-interpretación: "No se trata de adecuar el comprender y la interpretación a un determinado ideal de conocimiento. [...] Este círculo del comprender [...] es la expresión de la estructura existencial de la prioridad del Dasein mismo" (HEIDEGGER, 1997/1927, p. 176) ${ }^{24}$. El ser ya no es objeto y paralelamente la Verdad se metamorfosea, pasando de ser un reflejo para convertirse en un proyecto existencial irreducible al mero registro de datos objetivos.

Aun claves, las de Nietzsche y Heidegger no son las únicas críticas a la verdad como adaequatio que nutren la reflexión de Vattimo. Junto a ellas, no pueden olvidarse las sospechas que Marx vierte sobre la producción ideológica por parte de quienes dominan la realidad generando falsa conciencia y, a la postre, la alienación y el dominio de unos hombres (la clase capitalista) sobre otros (los trabajadores) (MARX, 2000, 1867). Y un segundo autor que influye enormemente en la verdad debilitada de Vattimo es Gadamer, a partir principalmente de su exposición de cómo la Filosofía identifica tradicionalmente la Verdad con el método, frente a la 'experiencia de verdad' como desplazamiento del Grund (fundamento) ${ }^{25}$. Dislocada la Verdad, el diálogo interpretativo gadameriano se asemeja más a una conversación abierta que al diálogo platónico ${ }^{26}$; los seres humanos son intérpretes que generan contenidos interpretativos y no sujetos de quienes se espera que algún día describan fielmente unos datos dados.

\section{La desmitificación de la Verdad: más allá de la interpretación}

La propuesta que deja Vattimo invita a participar en un juego siempre finito y nunca cerrado de interpretaciones sin espejos ${ }^{27}$, en una interacción convivencial de conversaciones abiertas y acuerdos colectivos parciales de los que surgen la insuficiente necesidad de la interpretación y el consenso, imprescindibles ambos para comprehender la verdad debilitada de Vattimo: "En la nueva condición del mundo

\footnotetext{
${ }^{23}$ Estos formalismos estéticos son palpables en algunas de las reflexiones de Vattimo.

${ }^{24}$ Ese 'conocimiento más originario' está ligado a la autenticidad (que no a la verdad) del ser, es decir, a su finitud, a su muerte, pues ningún ser puede evitarla. Esta impronta temporal del ser (humano) también está muy presente en Vattimo.

25 "El ideal de conocimiento perfilado por el concepto de 'método' consiste en recorrer una vía de conocimiento tan reflexivamente que siempre sea posible repetirla. [...] Lo metódico es poder recorrer de nuevo el camino andado, y tal es el modo de proceder de la ciencia. Pero eso supone necesariamente una restricción en las pretensiones de alcanzar la verdad" (GADAMER, 1998/1960, p. 54). "Gadamer retoma y enfatiza el término alemán Erfahrung -experiencia- [...] como 'ciencia de la experiencia de la conciencia'. [...] Experiencia de verdad [...], así, se define como un evento que transforma la conciencia, la desplaza y la disloca. Si esta definición de Erfahrung se toma en serio, y se lleva a sus últimas consecuencias, representa un radical elemento de desfundamentación. [...] La verdad entendida como 'dislocación' [...] no 'fundamenta' en ninguno de los sentidos que este término tiene en la tradición filosófica" (VATTIMO, 1992/1981, p. 89).

${ }_{26}$ "No hay un interlocutor que 'venza', y reduzca a sí al otro; la fusión de horizontes hermenéutica es el surgimiento de un tertium radicalmente nuevo que, por tanto, es juego también en cuanto 'pone en juego' los interlocutores en su ser" (VATTIMO, 1992/1981, p. 90).

27 "Se dice adiós a la verdad como espejamiento 'objetivo' de un 'dato' que, para ser descrito adecuadamente, debe ser fijado como estable, justo como “dato"” (Vattimo, en OÑATE \& ROYO, 2006, p. 77).
}

MARCOS, Jairo. Las víctimas ante el precipicio de la verdad: una cuestión de justicia tras el debilitamiento de Gianni Vattimo. Griot : Revista de Filosofia, Amargosa - BA, v.19, n.1, p.159-173, fevereiro, 2019. 
en el final de la metafísica, [... ] lo que cuenta ya no es la esperanza de encontrar una verdad al final de la discusión, sino más bien el propio hecho de que la discusión sea posible" (VATTIMO, 2010/2009, p. 129). Pero ¿acaso es suficiente con seguir dialogando eternamente? ¿Basta con abrazar la tolerancia de las autodenominadas sociedades multiculturales?

Por un lado, la interpretación lo "es todo: no existe experiencia de verdad que no sea interpretativa; no conozco nada si no me interesa, pero si me interesa es evidente que no lo miro con desinterés" (VATTIMO, 2010/2009, p. 79). Siempre condicionada, la hermenéutica no define con exactitud lo real, sino que interpreta lo que acontece desde determinados puntos de vista, a través de los cuales las verdades se instituyen "cada vez como auténtica novedad" (VATTIMO, 1991/1989, p. 85). No solamente el ser humano carece de una Verdad dada y objetiva, sino que además cualquier verdad va a ser posible únicamente como pretensión de verdad parcial, construyendo todas esas verdades provisionales la cartografía colectiva que habitan las personas, en el fondo, una conversación entre mapas diversos siempre por definir en cada momento.

Cada punto de vista que entreteje las verdades está atravesado por relaciones de poder, por juegos de intereses y ataduras varias. De ahí que la propuesta de las verdades plurales situadas radique su pretensión de veracidad en cada contingencia finita: se trata de introducir "casillas vacías, espacios en blanco, parpadeos, tiempos de pensamiento $[\ldots]$ o espacios vacíos que nos permitan [...]; una renuncia al grado máximo de velocidad de ahora a cambio de recuperar profundidad" (ZAFRA, 2017, pp. 186-187), frente a la correspondencia directa de único sentido del ' $p$ es verdadera si y solo si $p$ ?.

\begin{abstract}
Esto implica localizarse a una misma, en un sentido no individualista sino relacional. No se trata de decir que yo estoy aquí o allá, sino de explicar la posición que habito/habitamos (colectivamente) en esta compleja y jerárquica estructura social y hacerme/hacernos cargo de lo que miramos desde ahí, cómo lo miramos y para qué. Esta parcialidad, que ha de ser reconocida y de la que nos hemos de responsabilizar, no es un mal inevitable, sino un recurso epistemológico, porque permite ver junto a otrxs, sin pretender hablar por otrxs. Reconocer la contingencia del conocimiento y el carácter procreativo del lenguaje implica renuncia a la Verdad Universal y a dar respuestas válidas a través del tiempo y los espacios (PÉREZ-OROZCO, 2006/2004, p. 182).
\end{abstract}

Por eso, en la era de la post-Verdad, "sería un error pensar que solo es cuestión de encontrar la imagen justa y verdadera [...]. La realidad no es transmitida por lo que representa la imagen, sino por medio del desafío que la realidad constituye para la representación" (BUTLER, 2006/2004, p. 182). Ese espectáculo que, en sus actuales dimensiones aceleradas, massmediatizadas y viralizadas sin importar la verdad ni la mentira, no deja ver el rostro de las víctimas ni tampoco escuchar el grito de las periferias. La localización de los puntos de vista, siempre interpretables e interpretados, se inclina así por los horizontes de los subyugados, de las víctimas, sin con ello traicionar la finita contingencia de cada pretensión de verdad.

MARCOS, Jairo. Las víctimas ante el precipicio de la verdad: una cuestión de justicia tras el debilitamiento de Gianni Vattimo. Griot : Revista de Filosofia, Amargosa - BA, v.19, n.1, p.159-173, fevereiro, 2019. 


\section{La desmitificación de la Verdad: más acá del consenso}

Y de la interpretación al consenso, porque también es la de Vattimo una verdad consensuada, como característica necesaria pero insuficiente. El consenso se acerca a la descripción de 'amistad civil' imprescindible para que la sociedad abierta no se convierta en la "dictadura autoritaria de los expertos, los filósofos, los sabios, los comités centrales, [...] como si fuera posible hallar una verdad profunda [...] sobre la cual después todos concordemos" (VATTIMO, 2010/2009, p. 30). La verdad debilitada es consensuada, pues plantea un problema de interpretación colectiva, de construcción de paradigmas compartidos o al menos explícitamente reconocidos en y por la sociedad: "La sociedad es el lugar de la verdad" (LÈVINAS, 2002/1961, p. $123)^{28}$.

El mundo real ya no es el de las ideas platónicas, tampoco el de la tierra prometida por las religiones, ni el de las ideas claras y distintas de Descartes, ni el de las verdades experimentalmente verificadas del positivismo. El mundo es la historia que nos contamos los unos a los otros, mundo real, sí, pero debilitado interpretativa y consensualmente. Es el reto de las verdades en el pluriverso humano. Las verdades no se encuentran ni se poseen, sino que se habitan ${ }^{29}$ en el encuentro cara-a-cara, intersubjetivo y digno, con los Otros. La apertura hacia una concepción no metafísica de la verdad hace inútil cualquier intento de poseerla, siendo 'únicamente' posible habitar la verdad, ese irónico juego de interpretaciones "como horizonte y fondo en el cual uno se mueve discretamente" (VATTIMO, 1987/1985, p. 20). Por eso la "filosofía edificante espira a mantener una conversación más que a descubrir la verdad" (RORTY, 1989/1979, p. 337) ${ }^{30}$, sin que dicha conversación deba tender, ni siquiera idealmente, al consenso al que aspira cualquier Gran Relato ${ }^{31}$. Porque incluso el consenso corre el riesgo de constituir la enésima negación de la humanidad en cuanto ser arrojado como destino epocal.

La desmitificación del consenso no es baladí, por mucho que las teorías intersubjetivas de la verdad, entre ellas las consensualistas de $\mathrm{Apel}^{32}$ y Habermas ${ }^{33}$, e

\footnotetext{
${ }^{28}$ En esta misma línea levinasiana argumenta Vattimo: "El término 'verdad' plantea ahora [...] un problema de comunidad. Su sentido depende de la pertenencia a una comunidad, a un grupo [...]. La verdad interactúa hoy con la sociabilidad y la sociedad mucho más de lo que pasaba antes" (OÑATE Y ZUBÍA, 2010, p. 64).

29 "Habitar, [...] como metáfora para hablar de la verdad hermenéutica, habría que entenderla como habitar en una biblioteca: mientras la idea de 'verdad' como conformidad representa el conocimiento de lo verdadero como la posesión cierta de un 'objeto' mediante una representación adecuada, la verdad del habitar es más bien la competencia del bibliotecario, que no posee enteramente, en un acto puntual de comprensión transparente, la totalidad de los contenidos de los libros entre los cuales vive, ni siquiera los primeros principios de los que tales contenidos dependen" (VATTIMO, 1995/1994, p. 131).

30 Superando el ámbito de la metafísica, Rorty considera que la conversación y no la verdad es el "contexto último dentro del cual se debe entender el conocimiento" (RORTY, 1989/1979, p. 351).

31 “El concepto de 'conversación' nos permite desechar los grandes relatos modernos que trataban de explicar la totalidad de las prácticas sociales con arreglo a la conformidad de las mismas a un patrón universal aun cuando se toparan con culturas diferentes a la suya" (VATTIMO \& ZABALA, 2012/2011, pp. 152-153).

32 Para Apel, todo discurso racional presupone una comunidad racional de comunicación dispuesta a entenderse (la Kommunikationsgemeinschaft). Sin embargo, incluso Apel hace un guiño al disenso, al afirmar que, "bajo la presuposición empírico-pragmática de una formación de consenso por las presiones sociales del sistema, se puede usar emancipatoriamente [...] la formación de disensión contra la formación de consenso" (APEL, 1991/1987, p. $69)$.

33 La principal objeción que Habermas realiza a Apel es la dificultad de establecer dicha comunidad de comunicación en los diálogos reales, lo que se agrava en una situación tan desigual como la actual. Este obstáculo
}

MARCOS, Jairo. Las víctimas ante el precipicio de la verdad: una cuestión de justicia tras el debilitamiento de Gianni Vattimo. Griot : Revista de Filosofia, Amargosa - BA, v.19, n.1, p.159-173, fevereiro, 2019. 
incluyendo los matices de Vattimo por muy debilitada que acontezca la verdad en el pensiero debole, sobredimensionen sus virtudes. La deseada resolución final del consenso subestima la importancia del disenso, la necesidad de la polémica e incluso del conflicto a la hora de no cerrar la verdad definitivamente, ni siquiera bajo el amparo del acuerdo colectivo. "El diálogo filosófico [...] debiera hoy también ser inconcluyente. [...] Hoy por hoy, conviene que el diálogo quede abierto" (MUGUERZA, 2006/1990, p. 109). El consenso apenas es un lugar más donde habita la verdad o, formulado de otra forma, "el consenso por sí mismo no hace la verdad, ni ésta se puede identificar sin más con él -no vale la caricatura que pretende llevar la teoría consensualista a hacer de la verdad una cuestión de mayorías" (PÉREZTAPIAS, 2007, p. 65) ${ }^{34}$.

\section{Las verdades como caritas: la escucha del Otro plural}

Vattimo debilita la Verdad a partir de la apertura del Ser, del destino al que éste es irónicamente arrojado, de su historia finita y contextual como acontecimiento arrojado en la historia ${ }^{35}$. Frente a la Verdad como adecuación, el pensiero debole presenta su fidelidad a un ser que es ante todo evento, a una verdad que es principalmente juego de interpretaciones, conversación y apertura al Otro. No atender al destino del ser sería recaer en la mentira, como sucede con el espejamiento sistémico. El debilitamiento del Ser dibuja precisamente la parábola de la Verdad, que deja de ser adaequatio $^{36}$ y se convierte, secularizado el Ser objetivo y superada la Metafísica, en caritas, en la experiencia humana de "escuchar "al Otro como a ti mismo" (VATTIMO, 2010/2009, p. 91), con el acento puesto en ese matiz servicial ${ }^{37}$ que sale a relucir en presencia del Otro plural. A todo esto es hacia lo que apunta el consenso como lugar epistémico y ético de la verdad, si y solo si "se apoya en exigencias incondicionales de reconocimiento de la alteridad" (PÉREZ-TAPIAS, 2007, p. 66). Caritas como apertura al ser débil, al nos-Otras, las víctimas, hacia "la idea de

\footnotetext{
le empuja a distinguir entre la comunidad real y la comunidad ideal, siendo esta última el marco que finalmente hace posible el consenso (HABERMAS, 1999/1981).

${ }^{34}$ Hilando aún más fino, hace Tapias argumenta que 'la imperativa búsqueda del consenso', pero no el consenso en sí mismo, sí puede ser identificado como el lugar moral y epistémico de la verdad.

35 Resuenan aquí en Vattimo los ecos de Hegel: "Lo verdadero tiene la naturaleza de irrumpir y prevalecer cuando llega su tiempo, y [...] solo hace aparición cuando éste ha llegado" (HEGEL, 2010/1807, p. 137).

${ }^{36}$ La superación (Verwindung) de la Verdad como adaequatio no significa negar el avance de ciencias como la Matemática o la Medicina, sino que supone relativizar sus saberes respectivos. "Las verdades de sentido común y, sobre todo, de la ciencia, son verdades objetivas, pero solo como verdades secundarias -solo relativas a una 'apertura'- [...] Tales aperturas [...] deben pertenecer a una 'historia del Ser"' (FLORES, 2009/2007, p. 297). Al respecto de la ciencia, Vattimo argumenta su pérdida de confianza en la verdad como conformidad y correspondencia del siguiente modo: “¿Es esto peligroso? En absoluto. ¿Dónde demuestran los científicos la verdad de sus afirmaciones? En la comunidad científica. [...] Primero tengo que aprender el paradigma. [...] Todo acontece en la historia, ninguna idea se produce prescindiendo del momento histórico" (VATTIMO \& PATERLINI, 2008/2006, p. 58).

37 "El presente del nosotros, por el cual la verdad funciona, es un presente en constante movimiento; la verdad "sirve', no tiene nada de contemplativo" (VATTIMO, 2010/2009, p. 150). Este mismo matiz lo refleja ya Lèvinas, quien analiza la verdad no como develamiento, sino como la palabra de la Exterioridad que quiebra el solipsismo de la introspección de lo Mismo: "La aspiración a la exterioridad radical [...] constituye la verdad. [...] El pensamiento [...] guiado por el ideal de la objetividad no agota esta aspiración" (LÈVINAS, 2002/1961, pp. 54$55)$.
}

MARCOS, Jairo. Las víctimas ante el precipicio de la verdad: una cuestión de justicia tras el debilitamiento de Gianni Vattimo. Griot : Revista de Filosofia, Amargosa - BA, v.19, n.1, p.159-173, fevereiro, 2019. 
un proyecto de futuro como progresiva eliminación de los muros" (VATTIMO, 2010/2009, p. 93).

Verdad debilitada como resultado de un proceso de verificación cultural ${ }^{38}$; un acuerdo colectivo que tiene lugar en un determinado contexto histórico del que los intérpretes forman parte y en el que 'juegan' con diferentes mochilas, raíces, pertenencias e intereses que condicionan el juego de interpretaciones ${ }^{39}$ en el que cada punto de vista que entreteje las verdades está condicionado por intereses de poder en los que se pretende introducir transformaciones desde las víctimas. Por eso, la verdad debolista se funda en una cierta confianza en la historia del ser debilitado, acontecido socialmente como evento ${ }^{40}$.

Verdad más allá de la mera tolerancia. Y es que, momento previo a la aceptación del nos-Otras, las víctimas, la tolerancia es la actitud mínima de darle tiempo al Otro y supone otra teoría de la verdad que, a la mera e ingenua posesión de la Verdad, opone la pretensión de la verdad que afirma "acceder a la cosa misma, desde una lengua, desde un mundo cultural, desde un horizonte ontológico; pero sabe que tal acceso no es absoluto; es siempre finito, parcial, determinado por una cierta perspectiva social, histórica, psicológica, etc." (DUSSEL, 2007, p. 294). La tolerancia es empero una actitud mínima. En el encuentro con el Otro plural debe existir algo más que mera tolerancia, en cuanto la tolerancia supone una cierta indiferencia. La tolerancia pasiva de quien se desentiende del destino del Otro no basta.

La caritas o solidaridad (a la Horkheimer ${ }^{41}$ ) va más allá de la tolerancia [a la Voltaire (2010/1763, pp. 163-268)], porque "a la víctima no se la tolera, se colabora con ella a dejar de ser víctima" (DUSSEL, 2007, p. 299); pero también más allá de la fraternidad [a la Derrida (1998/1994, pp. 9-338)]. Es crítica, propositiva y responsable por las ausencias, poniéndose en su lugar, responsabilizándose por ellas no como lo Mismo, sino como las Otras, superando el reconocimiento de lo otro igual y afirmando su radical Exterioridad. Es el hacerse-cargo de los parias, de las periferias, de las víctimas. La referencia última es el dolor humano. Solidaridad no solo del aquí y del ahora, sino también con las generaciones futuras, hacia delante, y

\footnotetext{
38 Parte intrínseca de una época, los seres humanos habitan en la historia y habitan en la verdad. "En otros términos, toda objetividad 'natural' es también 'cultural', en el sentido de que no es la objetividad dada de una vez para siempre, que es o no es. Sino que es el resultado de una configuración dada y construida, y solo en el interior de dicha configuración se dan o no se dan ciertos eventos, se aplica el sí o el no" (VATTIMO, 2012/2000, p. 85).

39 "Nadie parte de cero, sino que se encuentra ya ligado por ciertos lazos de fidelidad, de pertenencia, por determinados vínculos. El horizonte retórico de la verdad -que también podría llamarse hermenéutico- se establece de esta manera libre, pero impura" (VATTIMO \& ROVATTI, 1990/1983, p. 39).

40 Ante el temor de que Vattimo inaugure "una nueva variante de adaequatio acontecida esta vez entre un intellectus comunitario y un Ser que se muestra [...] en términos de acontecimiento" (LLORENTE, 2016, p. 199), el filósofo turinés resulta esclarecedor: "La verdad no es fruto de interpretación porque a través del proceso interpretativo se logre aprehender directamente lo verdadero, como ocurre cuando la interpretación se concibe como desciframiento, desenmascaramiento, etc., sino porque solo en el proceso interpretativo [...] se constituye la verdad" (VATTIMO \& ROVATTI, 1990/1983, p. 39).

${ }^{41}$ Horkheimer piensa la solidaridad no solo proveniente de una clase social [caso de Marx (MARX \& ENGELS, 2005/1848)], "sino la que une a todos los hombres. [...] La [...] que brota del hecho de que los hombres tienen que sufrir, que mueren, que son seres finitos" (HORKHEIMER, 2000, p. 166). Donde dice 'hombre' debe leerse "ser humano'.
}

MARCOS, Jairo. Las víctimas ante el precipicio de la verdad: una cuestión de justicia tras el debilitamiento de Gianni Vattimo. Griot : Revista de Filosofia, Amargosa - BA, v.19, n.1, p.159-173, fevereiro, 2019. 
solidaridad con los muertos, hacia atrás ${ }^{42}$. Solidaridad con la humanidad y desde la humanidad $^{43}$. La caritas considera además que el Otro es un ser humano a quien se ha usurpado la posibilidad de vivir una vida que merezca la pena ser vivida ${ }^{44}$.

\section{A modo de conclusión: por justicia, no todo vale}

Pero la disolución de la Metafísica heideggeriana y la despedida de Dios nietzscheana parecen rescatar a la Verdad de las fauces de la Totalidad para, en su huida, conducirla por un callejón sin salida. Si únicamente en la eventualidad hermenéutica habita la verdad, Vattimo pareciera conducir a la verdad al precipicio relativista ${ }^{45}$. El suelo bajo los pies amenaza con derrumbarse llevándose consigo cualquier criterio de verdad, mientras las víctimas siguen ahí, sobreviviendo. Pero se trata, no hay que perderlo de vista, de un nihilismo positivo/activo en el que puede rastrearse un hilo conductor, pues Vattimo no supera la Verdad destruyéndola (Überwindung), sino a través de la fiesta de la memoria (Verwindung). Una irónica parábola cuyo rastro puede seguirse éticamente para tejer otras historias de vidas que merecen la pena ser vividas. Y la disolución de los absolutos afecta a la propia absolución, de manera que ésta tampoco puede absolutizarse ${ }^{46}$.

El hilo conductor de todas esas pretensiones de verdad no puede ser otro, una vez situada la verdad en las casillas del ser debilitado y no en los fundamentos últimos, que la necesidad de justicia por la humanidad alterativa del nos-Otras, las víctimas, mas sin atisbo alguno de dogmatismo ${ }^{47}$. Se trata de la humana responsabilidad de hacer valer el derecho de las periferias, de quienes sufrieron y sufren, de debilitar la Totalidad para abrirla y que las Exterioridades sean habitables como lugares epistémicos de verdad: "Las pretensiones de verdad implican el reconocimiento de la alteridad, pero más al fondo podemos encontrar que es la 'acogida' del otro, en su radical alteridad, como sujeto humano que nos interpela 'revelándose', lo que nos abre el espacio para la verdad" (PÉREZ-TAPIAS, 2007, p. $69)^{48}$. Por eso toda filosofía que se pretenda transformadora solo habitará las

\footnotetext{
42 En este sentido, más allá del marxismo ortodoxo, para el que el pretérito es algo definitivamente pasado y solo el futuro alberga la liberación.

${ }^{43}$ En este sentido, más allá de la religión, para la que la última instancia solo puede ser Dios.

${ }_{44}$ Esta inserción ética conlleva una relación intersubjetiva de con-vivencia que nada tiene que ver con el individualismo ético, a través de la cual la moral es la (auto)conciencia de cada miembro del lugar que guarda en dicha relación.

45 Vattimo es consciente de este peligro: "La conciencia del carácter interpretativo de toda nuestra experiencia parece dejar un vacío. ¿Cómo se evita [...] que se abra así el camino hacia una sociedad de lucha de todos contra todos, del puro conflicto entre intereses opuestos?" (VATTIMO, 2010/2009, pp. 27-28).

46 "Es aquí donde se impone la diferencia entre una ética posmetafísica y el puro y simple relativismo [...]: la constatación de que se ha disuelto la credibilidad de los primeros principios no se deja traducir en la asunción de nuestra condición histórica, y de nuestra pertenencia a una comunidad, como único absoluto" (VATTIMO, 2010/2009, p. 107).

47 "Esta ética hereda [...] algunos aspectos kantianos (en particular, el imperativo categórico en términos de respeto por el otro: considera la humanidad en ti y en los otros siempre como fin, nunca como simple medio), aunque despojados de todo residuo dogmático. [...] Respeto por el otro es sobre todo reconocimiento de la finitud que a ambos nos caracteriza y que excluye toda superación definitiva de la opacidad que cada uno lleva consigo" (VATTIMO, 2010/2009, pp. 112-113).

${ }^{48}$ Pérez-Tapias sigue en este punto el concepto levinasiano de verdad como revelación (LÈVINAS, 2002/1961, pp. 104-161, alejándose al mismo tiempo de la Verdad como desvelamiento propuesta por Heidegger (1997/1927).
}

MARCOS, Jairo. Las víctimas ante el precipicio de la verdad: una cuestión de justicia tras el debilitamiento de Gianni Vattimo. Griot : Revista de Filosofia, Amargosa - BA, v.19, n.1, p.159-173, fevereiro, 2019. 
verdades a costa de buscar la justicia ${ }^{49}$. "Para sobrevivir, por dignidad. Es una cuestión de justicia. [...] Donde no hay justicia no cabe la verdad" (PÉREZTAPIAS, 2007, p. 59) ${ }^{50}$.

La aparición de la ética en la compleja maraña de desfundamentaciones y despedidas en las que se enreda la verdad debolista es únicamente factible a través de la inexpugnable finitud humana. Precisamente porque los puntos de vista son múltiples, sería perpetuar el error absolutista desanclar la verdad de la abstracta objetividad (la ficticia atalaya del nowhere) para atarla en cualquier sitio (la aparente tolerancia del everywhere de la que Vattimo se escaquea recayendo en un formalismo insuficiente para las víctimas ${ }^{51}$ ). Para ser transformadora, la Verdad deja de ser absoluta, incluso de pretenderlo, sin perder por ello la referencia de criterios que habitan las vidas humanas dignas, del nos-Otras, las víctimas, como fuente corporal. Origen y no fundamento (Grund), condición de posibilidad de verdades situadas y no fiel reflejo de lo ya-dado-para-siempre.

La justicia como condición de verdades plurales o las verdades plurales como reconocimiento de la justicia abren el espacio del sentido de verdad a un ámbito distinto, al de las alteridades antropológicas del Otro plural, no desde lo Mismo, sino desde las propias Exterioridades, desde lo radicalmente Otro levinasiano ${ }^{52} \sin$ el cual no es posible habitar la verdad. "Más al fondo que la reciprocidad del reconocimiento, incluso como a priori suyo, está la interpelación del otro con la justicia que demanda. Ella exige la verdad porque la hace posible" (PÉREZTAPIAS, 2007, p. 69).

Es humanamente transformador desfundamentar la Verdad sin acercarla al relativismo absoluto, abogando por su precaria y temporal universalización ${ }^{53}$ a través de su acercamiento al Otro plural como origen ético consciente de su finita y doliente corporalidad. Sin nos-Otras, las víctimas, no hay verdad, pero ninguna víctima concreta, individual o colectiva, puede absolutizarse como Exterioridad privilegiada y excluyente. La epifanía del Otro como lugar en el que habitan las verdades en relación con la justicia siempre está abierta a la irrupción del tercero, “desde el que la demanda de justicia se hace aún más densa y urgente" (PÉREZTAPIAS, 2007, p. 76).

\footnotetext{
49 "El filósofo debería rebasar el horizonte ontológico de la verdad y abrirse al ámbito de la justicia" (DUSSEL, 1973, p. 51).

50 Más adelante, Pérez-Tapias vuelve sobre este mismo argumento: "Sin el restablecimiento de condiciones de vida digna para todos, que es lo que entraña un objetivo de justicia, no es posible que se abra paso la verdad en nuestras comunidades fácticas de hablantes. Sin atender a las exigencias morales del otro estamos bajo situaciones de dominio distorsionantes de toda comunicación" (PÉREZ-TAPIAS, 2007, p. 67).

51 "El resultado nihilista de la hermenéutica [...] no significa no tener ya criterios de verdad, sino solo que estos criterios son históricos y no metafísicos; ciertamente no vinculados al ideal de la 'demostración', sino más bien orientados a la persuasión. La verdad es un asunto de retórica, de aceptación compartida" (VATTIMO, 2013/2012, p. 241).

52 La cuestión de la Verdad queda desgajada así de (la lógica de) la Totalidad. Del hegeliano "lo verdadero es el todo" (HEGEL, 2010/1807, p. 75), al adorniano "el todo es lo no verdadero" (ADORNO, 2001/1951, p. 48). El infinito de Lèvinas condensa esta revelación ética del otro como epifanía decisiva: "La verdad [del Otro] supone la justicia" (LÈVINAS, 2002/1961, p. 112).

53 "La concepción hermenéutica de la verdad no es de ninguna manera una reivindicación de 'lo local' frente a 'lo global', [...] para la cual los enunciados estarían siempre solamente dentro de un horizonte delimitado" (VATTIMO, 1995/1994, p. 145).
}

MARCOS, Jairo. Las víctimas ante el precipicio de la verdad: una cuestión de justicia tras el debilitamiento de Gianni Vattimo. Griot : Revista de Filosofia, Amargosa - BA, v.19, n.1, p.159-173, fevereiro, 2019. 


\section{Referencias}

ADORNO, Theodor W. Minima moralia: reflexiones desde la vida dañada. Trad. Joaquín Chamorro. Madrid: Taurus, 2001 [Edición original: 1951].

AGUSTÍN, San. Las confesiones. Trad. Agustín Uña. Madrid: Tecnos, 2007 [Edición original: ca. 397-398 d.e.c.].

APEL, Karl-Otto. Teoría de la verdad y ética del discurso. Trad. Norberto Smilg. Barcelona: Paidós, 1991 [Edición original: 1987].

BUTLER, Judith. "Vida precaria". Vida precaria: el poder del duelo y la violencia. Trad. Fermín Rodríguez. Buenos Aires: Paidós, 2006 [Edición original: 2004]. 163187.

CERVERA, José. "Contra la verdad, las noticias falsas no existen". Cuadernos de periodistas, $\mathrm{n}^{\mathrm{o}}$ 35. Madrid: Asociación de la Prensa de Madrid, 2017. 9-14.

COMTE, Auguste. Discurso sobre el espíritu positivo. Trad. Eugenio Moya. Madrid: Biblioteca Nueva, 1985 [Edición original: 1844].

DEBORD, Guy. La sociedad del espectáculo. Trad. Rodrigo Vicuña. Santiago de Chile: Naufragio, 1995 [Edición original: 1967].

DERRIDA, Jacques. "Políticas de la amistad". Políticas de la amistad; seguido de El oído de Heidegger. Trad. Patricio Peñalver. Madrid: Trotta, 1998 [Edición original: 1994]. 9-338.

DUSSEL, Enrique. Caminos de liberación latinoamericana I. Interpretación históricoteológica de nuestro continente latinoamericano. Buenos Aires: Latinoamérica Libros, 1972.

DUSSEL, Enrique. Materiales para una política de la liberación. México D.F.: Plaza y Valdés, 2007.

DUSSEL, Enrique. Para una ética de la liberación latinoamericana. II Vol. Buenos Aires: Siglo Veintiuno Argentina, 1973.

FLORES, Paolo. "Gianni Vattimo; o más bien, la hermenéutica como primacía de la política". Debilitando la filosofía: ensayos en honor a Gianni Vattimo. Ed. Santiago Zabala. Trad. Francisco Javier Martínez. Barcelona: Anthropos, 2009 [Edición original: 2007]. 290-311.

GADAMER, Hans-Georg. “¿Qué es la verdad?”. Verdad y método. Fundamentos de una hermenéutica filosófica. Trad. Manuel Olasagasti. Salamanca: Sígueme, 1998 [Edición original: 1960]. 51-62.

HABERMAS, Jürgen. Teoría de la acción comunicativa. Trad. Manuel Jiménez. Madrid: Taurus, 1999 [Edición original: 1981].

HABERMAS, Jürgen. Verdad y justificación: ensayos filosóficos. Trads. Pere Fabra y Luis Díez. Madrid: Trotta, 2002 [Edición original: 1999].

HEGEL, G. W. Friedrich. Lecciones sobre la filosofía de la historia universal. Trad. José Gaos. Madrid: Alianza, 1986 [Edición original: 1837].

HEGEL, G. W. Friedrich. Fenomenología del espíritu. Trad. Antonio Gómez. Madrid: Abada, 2010 [Edición original: 1807].

HEIDEGGER, Martin. Ser y tiempo. Trad. Jorge Eduardo Rivera. Santiago de Chile: Universitaria, 1997 [Edición original: 1927].

HORKHEIMER, Max. Anhelo de justicia. Teoría crítica y religión. Trad. Juan José Sánchez. Madrid: Trotta, 2000. 
KANT, Immanuel. Crítica de la razón pura. Trad. Mario Caimi. Buenos Aires: Colihue, 2007 [Edición original: 1781].

LÈVINAS, Emmanuel. Totalidad e infinito: ensayo sobre la exterioridad. Trad. Miguel García-Baró. Salamanca: Sígueme, 2002 [Edición original: 1961].

LLORENTE, Jaime. “¿Puede la hermenéutica nihilista de Gianni Vattimo justificar racionalmente sus últimas posiciones políticas?" Las Torres de Lucca, Vol. 5 n$^{\circ} 8$. $2016 . \quad$ 185-226. Disponible en: www.lastorresdelucca.org/index.php/ojs/article/view/101/94.

MARX, Karl. El capital: crítica de la economía política. Trad. Vicente Romano. Madrid: Akal, 2000 [Edición original: 1867].

MARX, Karl, y Friedrich Engels. El manifiesto comunista. Trad. Jesús Izquierdo. Madrid: Turner, 2005 [Edición original: 1848].

MUGUERZA, Javier. Desde la perplejidad: ensayos sobre la ética, la razón y el diálogo. Madrid: Fondo de Cultura Económica, 2006 [Edición original: 1990].

NIETZSCHE, Friedrich. "Cómo el 'mundo verdadero' acabó convirtiéndose en una fábula". Crepúsculo de los ídolos o Cómo se filosofa con el martillo. Trad. Andrés Sánchez. Madrid: Alianza, 2001 [Edición original: 1889]. 57-58.

NIETZSCHE, Friedrich. "Del alma de los artistas y escritores". Humano, demasiado humano. Un libro para espíritus libres. Trad. Alfredo Brotons. I Vol. Madrid: Akal, 2001 [Edición original: 1878]. 119-150.

OÑATE Y ZUBÍA, Teresa. "Diálogo con Vattimo: El destino de Europa". El retorno teológico-político de la inocencia (los hijos de Nietzsche II). Madrid: Dykinson, 2010. 61-90.

PÉREZ-OROZCO, Amaia. Subversión feminista de la economía: aportes para un debate sobre el conflicto capital-vida. Madrid: Traficantes de Sueños, 2014. Disponible en: $\quad$ http://riemann.upo.es/personal-wp/congreso-economiafeminista/files/2013/10/PerezOrozco_Amaia.pdf.

PÉREZ-TAPIAS, José Antonio. "Verdad de la justicia y poder de la mentira. Reflexión ético-política desde Lèvinas". Del bienestar a la justicia: aportaciones para una ciudadanía intercultural. Madrid: Trotta, 2007. 45-95.

PLATÓN. La República. Trad. Antonio Gómez. México D. F.: Universidad Nacional Autónoma de México, 2000 [Edición original: ca. 380 a.e.c.].

PLATÓN. "Menón”. Diálogos. II Vol. Trads. J. Calonge, et al. Madrid: Gredos, 1987 [Edición original: 385 a.e.c.]. 273-337.

POPPER, Karl R. La sociedad abierta y sus enemigos. Trad. Eduardo Loedel. Barcelona: Paidós, 2006 [Edición original: 1945].

RORTY, Richard. La filosofía y el espejo de la naturaleza. Trad. Jesús Fernández. Madrid: Cátedra, 1989 [Edición original: 1979].

TARSKI, Alfred. "La concepción semántica de la verdad y los fundamentos de la semántica". A Parte Rei: revista de filosofía, no 6 Trad. Paloma García. 1999 [Edición original: 1944]. 1-30. Disponible en: https://ialnet.unirioja.es/servlet/articulo?codigo $=3867056 \&$ orden $=336201 \&$ info $=$ lin k.

UNAMUNO, Miguel de. San Manuel Bueno, mártir. Literanda, 2017. [Edición original: 1931]. 
VATTIMO, Gianni. Adiós a la verdad. Trad. María Teresa D'Meza. Barcelona: Gedisa, 2010 [Edición original: 2009].

VATTIMO, Gianni. De la realidad: fines de la Filosofía. Trad. Antoni Martínez. Barcelona: Herder, 2013 [Edición original: 2012].

VATTIMO, Gianni. El fin de la Modernidad. Nihilismo y hermenéutica en la cultura posmoderna. Trad. Alberto L. Bixio. Barcelona: Gedisa, 1987 [Edición original: 1985].

VATTIMO, Gianni. Ética de la interpretación. Trad. Teresa Oñate. Barcelona: Paidós, 1991 [Edición original: 1989].

VATTIMO, Gianni. Más allá de la interpretación. Trad. Pedro Aragón. Barcelona: Paidós, 1995 [Edición original: 1994].

VATTIMO, Gianni. Más allá del sujeto: Nietzsche, Heidegger y la hermenéutica. Trad. Juan Carlos Gentile. Barcelona: Paidós, 1992 [Edición original: 1981].

VATTIMO, Gianni. Vocación y responsabilidad del filósofo. Trad. Antoni Martínez. Barcelona: Herder, 2012 [Edición original: 2000].

VATTIMO, Gianni. “¿Adiós a la verdad?” Ética de las verdades hoy: homenaje a Gianni Vattimo. Trad. Teresa Oñate. Eds. Teresa Oñate y Simón Royo Hernández. Madrid: UNED, 2006. 71-80.

VATTIMO, Gianni, y Pier Aldo Rovatti. El pensamiento débil. Trad. Luis de Santiago. Madrid: Cátedra, 1990 [Edición original: 1983].

VATTIMO, Gianni, y Piergiorgio Paterlini. No ser Dios. Una autobiografía a cuatro manos. Trads. Rosa Rius y Carme Castells. Barcelona: Paidós, 2008 [Edición original: 2006].

VATTIMO, Gianni, y Santiago Zabala. Comunismo hermenéutico: de Heidegger a Marx. Trad. Miguel Salazar. Barcelona: Herder, 2012 [Edición original: 2011].

VOLTAIRE. "Tratado sobre la tolerancia". Cartas filosóficas; Tratado sobre la tolerancia; Diccionario filosófico; Opúsculos; Cuentos; Memorias para servir a la vida de Voltaire escritas por él mismo. Trad. Carlos R. de Dampierre. Ed. Martí Domínguez. Madrid: Gredos, 2010 [Edición original: 1763]. 163-268.

VV.AA. En la era de la posverdad: 14 ensayos. Barcelona: Calambur, 2017.

WITTGENSTEIN, Ludwig. Investigaciones filosóficas. Trad. Alfonso García. Barcelona: Altaya, 1999 [Edición original: 1953].

WITTGENSTEIN, Ludwig. Tractatus logico-philosophicus. Trads. Jacobo Muñoz y Isidoro Reguera. Madrid: Alianza, 2010 [Edición original: 1921].

Autor(a) para correspondência: Jairo Marcos, Universidad Nacional de Educación a Distancia, Facultad de Filosofía. Edificio de Humanidades. C/ Paseo Senda del Rey, 7. 28040-Madrid, Espanha. jmarcos@desplazados.org 